\title{
FRACTOGRAPHIC FEATURES OF THE FATIGUE FRACTURE OF NITINOL ALLOY
}

\author{
V.P. Iasnii, ${ }^{1,2}$ H. M. Nykyforchyn, ${ }^{3}$ O. Z. Student, ${ }^{3}$ and L. M.Svirska ${ }^{3} \quad$ UDC 620.193.81: 620.197.6
}

\begin{abstract}
We study the macro- and microfractographic features of the mechanism of initiation and propagation of fatigue cracks in the nitinol alloy after its testing for low-cycle fatigue and analyze possible influence of the structural and phase transformations caused by the cyclic deformation of nitinol on the fractographic features of its fatigue fracture. Thus, almost parallel transcrystalline facets of brittle cleavage located in almost mutually perpendicular planes along the entire length of martensite crystals are observed within the boundaries of separate grains (first of all, in the early stages of fracture). The signs of shallow fatigue striations are detected (but rarely) in the zone of the stable growth of the fatigue crack. The spacing of these striations approximately corresponds to a crack-growth rate of $8 \cdot 10^{7} \mathrm{~m} / \mathrm{cycle}$. It is suggested that the deformation transformation of austenite into martensite can also distort the classical deformation mechanism of formation of the fatigue striations. In the zones of fractures with uncontrolled crack growth, the elements of ductile pit topography are predominant, which is typical of the fracture surfaces of specimens destroyed under active loading.
\end{abstract}

Keywords: shape-memory alloy, martensitic transformation, fractography, hydrogen effect, plastic deformation.

Alloys with the properties of pseudoelasticity [1] and shape memory [2] are now used in various branches of engineering more and more extensively [3-6]. Among these alloys, we can especially mention nitinol (Ni-Ti alloy). Its ability to resist to cyclic loads is regarded as one of its most important mechanical characteristics [7] specifying its serviceability as a functional material with hyperelasticity effect.

Numerous specific features of pseudoelastic nitinol under the conditions of low-cycle loading were determined in [8]. In particular, these features include a rapid decrease in the amplitude of deformation and an increase in the level of residual strains observed for about ten loading cycles and is terminated by the region of stabilization of these characteristics. Note that the pseudoelastic behavior of these alloys is explained by the direct and inverse austenite-martensite transformations. Under the influence of deformation caused by loading, we observe the direct phase transformation. In the course of unloading, we observe a subsequent recovery of deformation of the metal even at temperatures higher than the temperature of termination of the austenitic transformation. As a result of these structural and phase transformations, the Ni-Ti alloy may recover up to 6-8\% of the level of strains.

The signs of embrittlement of nitinol are connected, first of all, with a decrease in the energy consumption of the fracture processes. The fractographic analysis of the fracture surfaces reveals these specific features. In particular, this is well visible in the example of influence of the process of hydrogenation on the character of fracture of the specimens subjected to intense stretching [9].

\footnotetext{
${ }^{1}$ I. Pulyui Ternopil National Technical University, Ternopil, Ukraine.

${ }^{2}$ Corresponding author; e-mail: v.iasnii@gmail.com.

${ }^{3}$ Karpenko Physicomechanical Institute, Ukrainian National Academy of Sciences, Lviv, Ukraine.
}

Translated from Fizyko-Khimichna Mekhanika Materialiv, Vol. 55, No. 5, pp. 148-153, September-October, 2019. Original article submitted April 17, 2019. 
It is clear that, under the conditions of cyclic deformation, which not only exhausts plasticity but also intensifies structural-phase transformations in nitinol, one may expect the appearance of the fractographic signs of embrittlement. Their detection should facilitate the procedure of identification of the mechanism of fracture of nitinol. The aim of the present work is to study the appearance of fractographic signs of the fatigue fracture of nitinol.

\section{Testing Method}

In our studies, we used nitinol alloy $\left(\mathrm{Ni}_{55.8} \mathrm{Ti}_{44.2}\right)$ in the form of a rod $\varnothing 8 \mathrm{~mm}$. From this rod, we prepared smooth cylindrical specimens whose diameter and the length of the working part were 4 and $12.5 \mathrm{~mm}$, respectively. The specimens were cyclically loaded by axial tension at a frequency of $0.5 \mathrm{~Hz}$ for the load ratio $R=0$. In the tests, the variations of loads in a cycle were controlled by displacements of the holders. The specimens were tested at a temperature of $0^{\circ} \mathrm{C}$ in a chamber with distilled water containing pieces of ice [8]. The strength characteristics of nitinol at this temperature are as follows: $\sigma_{0.2}=447 \mathrm{MPa}, \sigma_{\mathrm{u}}=869 \mathrm{MPa}$.

The fractographic specific features of the fracture surfaces of specimens were studied in an EVO-40XVP scanning electron microscope. For this purpose, we chose fracture surfaces of two specimens that were tested for different initial amplitudes of cyclic deformation $(\Delta \varepsilon=6.5$ and 3.1\%). These specimens failed after 773 and 2053 loading cycles, respectively $[10,11]$, which corresponds to the conditions of low-cycle fatigue. In what follows, these specimens are denoted by $A$ and $B$.

\section{Results of Fractographic Investigations}

The macroscopic fracture surfaces of both analyzed specimens are characterized by the normal orientation of the fracture planes. Note that the fracture processes originate from the lateral surfaces. In the fracture surface of the specimen $B$ destroyed for the lower amplitude of deformation $\Delta \varepsilon$ in a loading cycle than for the specimen $A$, we observe an almost continuous front from the surface fatigue crack. In this case, the topography of the fracture surface has typical signs of brittle fracture (Fig. 1a).

A well-visible boundary separates a sickle-shaped zone of initiation of the fracture process from the neighboring zone of its subsequent rapid propagation with clear signs of embrittlement on the macrolevel. The presence of embrittlement manifests itself in the form of festoons separated one from each other by rupture crests. They diverge in a fan-shaped manner from the zone of fracture initiation (Figs. 1a, b). On the macrolevel, this surface topography is typical of the fracture surfaces of specimens made of steels degraded after long-term operation and, in particular, after impact tests. Note that the contact of crack faces in each cycle of loading of the specimens damages their fracture surfaces. First of all, this is true for the fracture surfaces of the specimen $B$, which can be explained by the lower crack opening displacement (due to the lower amplitude $\Delta \varepsilon$ in the course of the tests). Therefore, we analyzed the fracture surface of the specimen $A$ in more detail and for a higher resolving power. This enabled us to establish the relationship between the topography of the fracture surface and the structure of grains in the alloy. Thus, it was shown that the sizes of fatigue-fracture facets are comparable with the sizes of grains in the structure of the alloy (Figs. 1c, d). Moreover, the indicated specific feature is even more pronounced in the fracture surfaces of the specimen $A$ tested at higher strain amplitudes. Within the limits of separate grains, the fracture facets are clearly bordered by well-visible rupture crests, which serves as a sign of significant orientation mismatch of the planes with minimal resistances to the propagation of fracture in neighboring grains.

The fatigue fracture surfaces of nitinol are characterized by the radial (relative to the zone of fracture initiation) orientation of elements (Fig. 2). The appearance of these elements is similar to the so-called festoons, which 

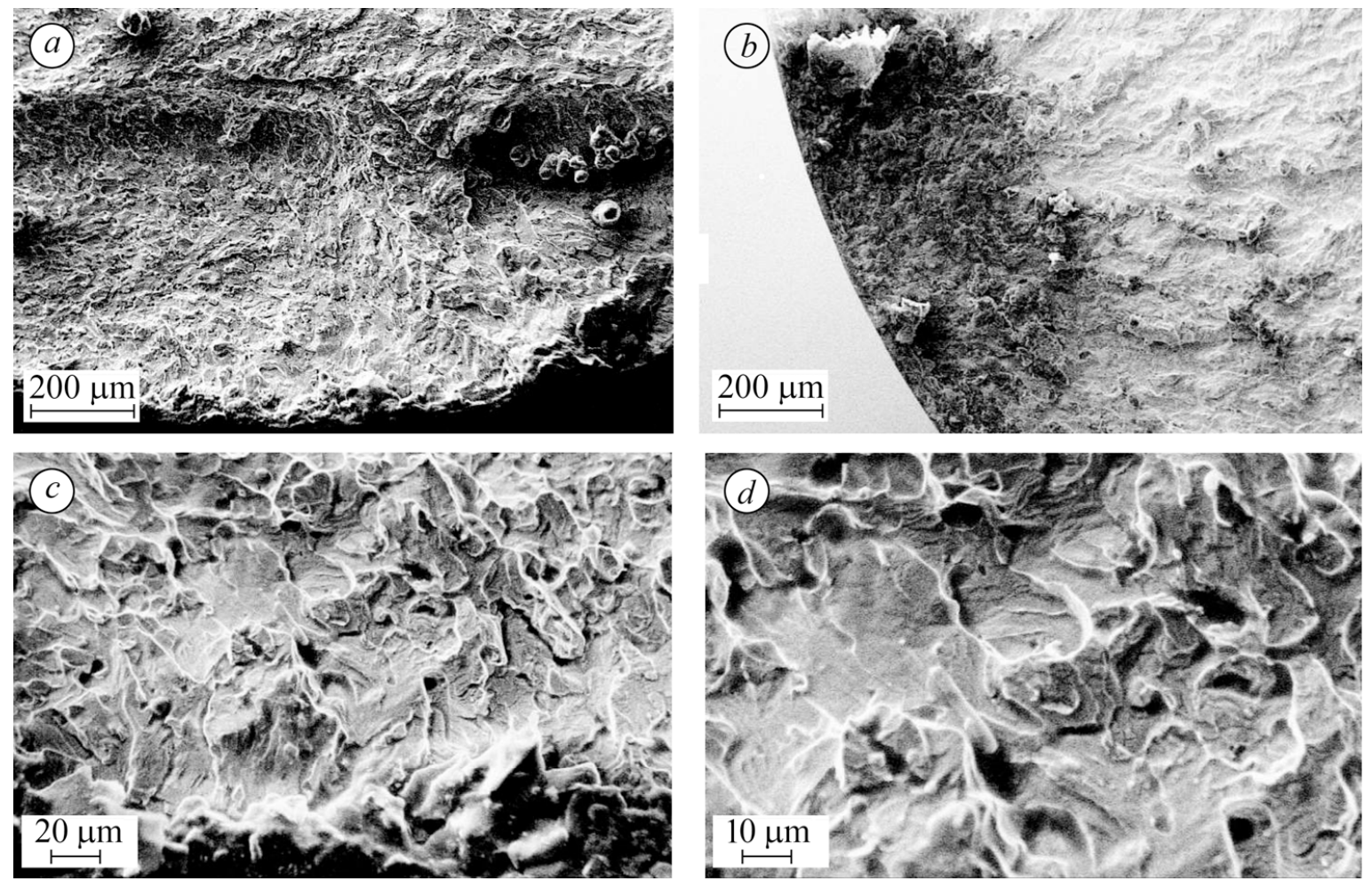

Fig. 1. Microfractograms of fracture surfaces of specimens $A \quad(a, c, d)$ and $B \quad(b)$ in the zones of fatigue-fracture initiation.
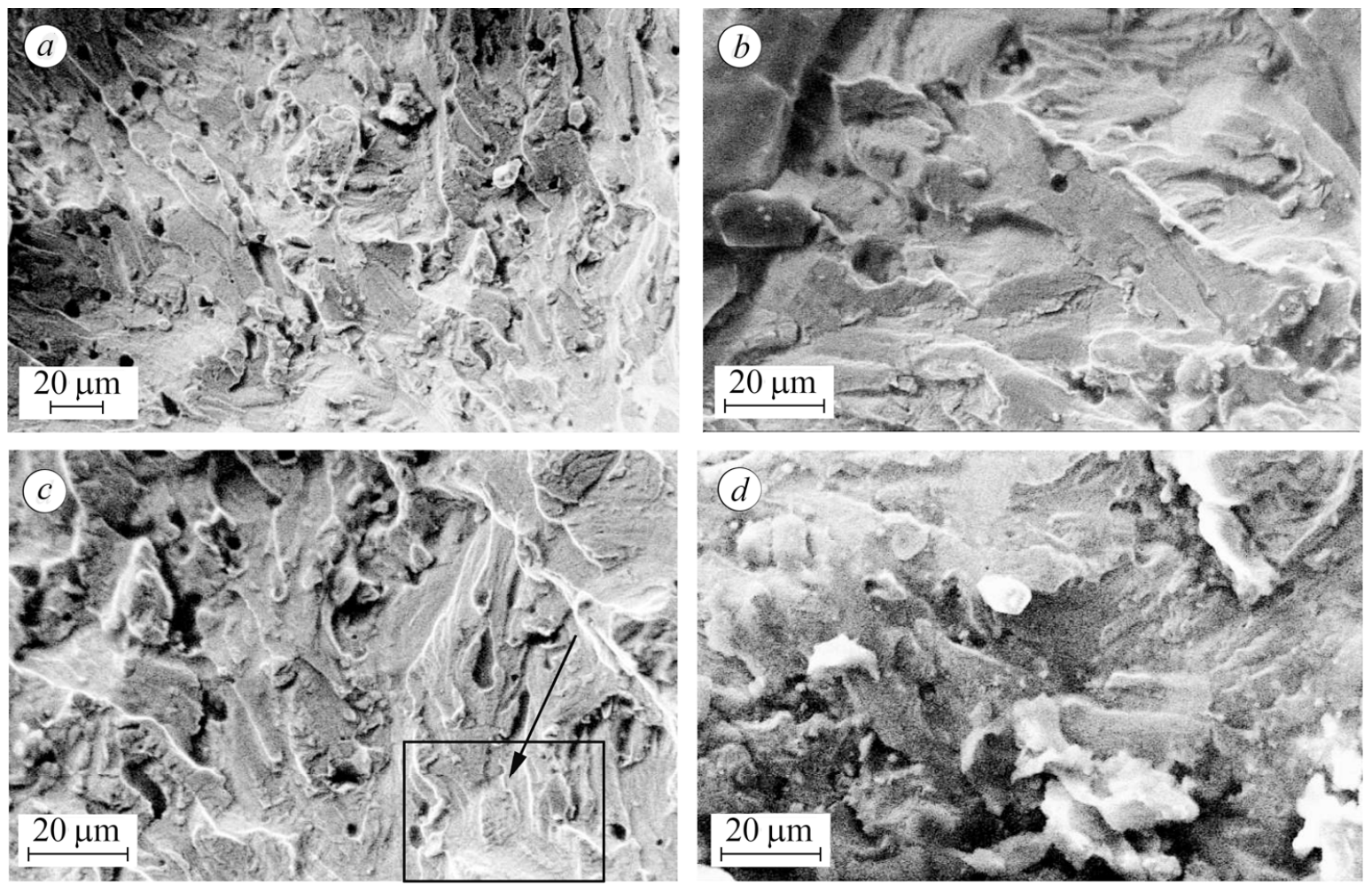

Fig. 2. Microfractograms of the fracture surfaces of specimens $A(a-c)$ and $B($ d) in the zones of stable growth of fatigue cracks. 
are usually formed in the fatigue fracture surfaces of the major part of structural materials [12-14]. For high rates of crack propagation (in fact, from the onset of the second part of the kinetic diagram of fatigue fracture), these festoons are crossed (in the transverse direction) mainly by fatigue striations whose steps determine the rates of propagation of the fracture processes in each loading cycle.

However, in the fatigue fracture surfaces of nitinol, these elements were observed, in fact, as an exception. This can be explained by the fact that they are formed on the surface under the conditions of fatigue fracture and then, most likely, damaged due to the effect of crack closure observed in the course of contact of the crack faces in a loading cycle. We also note that the depth of fatigue striations on the fracture surface attains $30 \mathrm{~nm}$ [15]. The opening displacement of the crack faces under axial tension is also insignificant. Under these conditions, it is difficult to avoid the possibility of contact of the crack faces and, hence, the low-height surface topography of striations is, in fact, destroyed. Nevertheless, the presence of isolated and small areas of fracture with traces of very fine striations was observed in some festoons in the fatigue fracture surfaces (Fig. 2c, within the limits of the outlined section). On the average, their step is equal to $0.8 \mu \mathrm{m}$, which corresponds to a crack growth rate of $8 \cdot 10^{-7} \mathrm{~m} /$ cycle (this velocity is traditionally regarded as the middle of the second section in the kinetic diagram of fatigue fracture for structural materials). We also take into account the possibility of intensification of the strain-induced phase transformation of austenite into martensite by cyclic deformation of nitinol in the process zone of a fatigue crack. In view of this fact, the classical deformation mechanism of formation of the striations can be also distorted in embrittled martensite and acquire certain atypical signs of shallow brittle striations.

In the stage of stable fatigue growth, both specimens reveal similar fractographic signs in the form of almost parallel crests whose orientation changes in passing through the grain boundaries. However, in the specimen A, these crests are well outlined and not always rectilinear (Fig. 2a). At the same time, in the specimen $B$, they are always rectilinear and less prominent (Fig. 2d), which is explained, most likely, by the lower level of cyclic loading.

In [16], the rupture crests almost parallel within the limits of separate grains were observed as a result of tensile testing of preliminarily hydrogenated specimens at a temperature of $0^{\circ} \mathrm{C}$. Under static loading, the height of this topography is much higher than under cyclic loading, which is explained by the lower level of the latter. Similar crests were not detected in the fracture surfaces of nonhydrogenated specimens subjected to intense stretching. Hence, the appearance of these crests in hydrogenated nitinol is connected with the facilitation of phase transition in it under the influence of hydrogen. Thus, it is logical to relate similar elements in the form of parallel rupture crests revealed in the fatigue fracture surfaces of the specimens (Figs. 2b, d) also to the structural-phase transformation of austenite into martensite and to the formation of parallel cleavage facets along the boundaries of martensite crystals. Note that cyclic loads may promote the realization of this transformation with characteristic signs of the embrittlement of nitinol.

As for the specific features of fracture in the central zones of both fracture surfaces corresponding to the stage of uncontrolled crack propagation (Fig. 3), the elements of ductile pit fracture typical of the fracture surfaces of specimens tested under active loading were predominant in both cases. Here, we only mention a less pronounced topography of the rupture crests separating neighboring pits in the specimen $A$ as compared with the specimen $B$. This may serve as an indication of a higher rate of fracture in the specimen $A$ for the higher strain amplitude in a loading cycle.

In addition, we detected a significant number of large pits in the specimen $A$ whose sizes are comparable with the sizes of titanium inclusions revealed in the structure of alloy in [9]. However, no inclusions of this kind were detected in these pits (Fig. 3a).

It is possible that the higher strain amplitude promotes the decohesion of inclusions from the matrix accompanied by the formation of large pits, which create additional stress concentration and, hence, may serve as an additional factor of embrittlement of the material. 

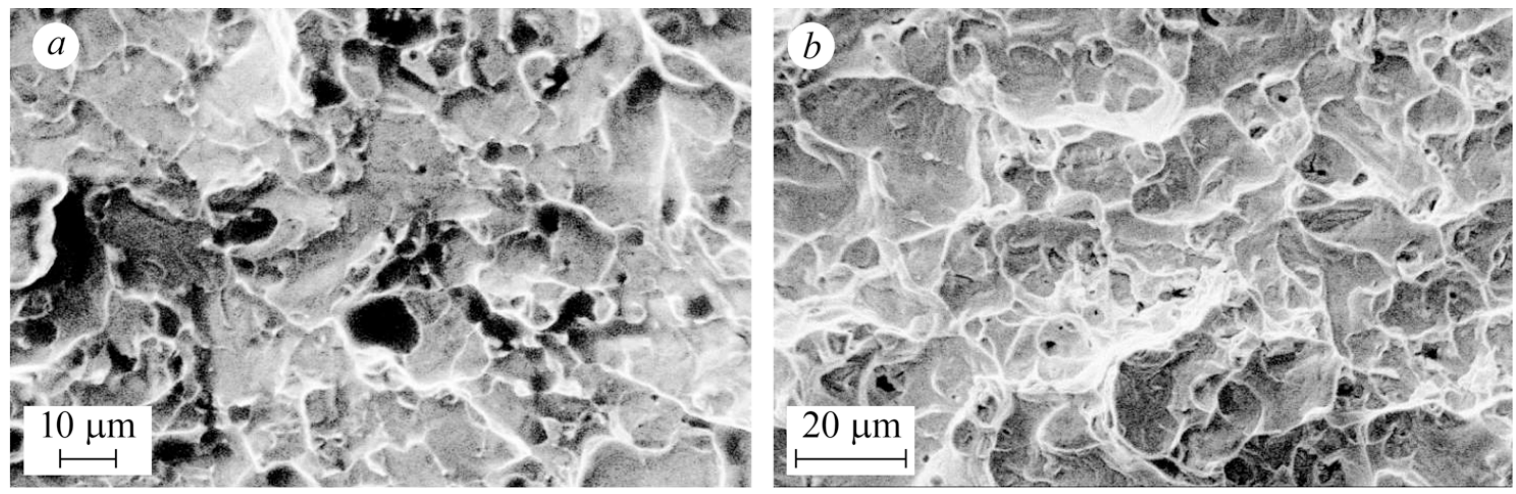

Fig. 3. Microfractograms of the fracture surfaces of specimens $A$ (a) and $B$ (b) in the zones of spontaneous fracture.

\section{CONCLUSIONS}

Independently of the initial amplitude of cyclic deformation of nitinol specimens by axial tension, their fractures originate from the external surface as a result of the formation of segment-like sections from various sites along the perimeter of the fracture surface. These sections merge and form a continuous front of fracture. Inside the zones of initiation, we reveal parallel facets outlined by prominent rupture crests whose orientation varies from grain to grain. This serves as a sign of significant orientation mismatch of the planes with minimum resistance to the propagation of fatigue fracture in the neighboring grains of the nitinol alloy. Within the limits of separate grains (especially in the early stages of fracture), we also revealed almost parallel transcrystalline facets of brittle cleavage (along martensite crystals) separated from each other by rupture crests also formed by the mechanism of cleavage. Their appearance is explained by the embrittlement of nitinol as a result of the structural-phase transformation of austenite into martensite caused by cyclic straining of the metal at the crack tip.

On the surfaces of festoons elongated in the direction of crack propagation and located in the zone of stable fatigue fracture, we rarely detected the traces of very fine fatigue striations oriented normally to the festoons. The step of these striations approximately corresponds to the crack growth rate equal to $8 \cdot 10^{-7} \mathrm{~m} /$ cycle. However, in general, the presence of the effect of crack closure, which cannot be avoided for small crack opening displacements observed under the conditions of cyclic loading of the specimens by uniaxial tension, levels the low-height surface topography of the fracture surfaces and destroys, first of all, the traces of striations. It is possible to assume that the deformation transformation of austenite into martensite may also distort the classical deformation mechanism of formation of fatigue striations.

In the zone of fracture surfaces with uncontrolled crack propagation, the elements of ductile pit topography typical of the specimens failed under the action of active loading are predominant.

\section{REFERENCES}

1. G. Kang and D. Song, "Review on structural fatigue of NiTi shape memory alloys: Pure mechanical and thermo-mechanical ones," Theor. Appl. Mech., 5, No. 6, 245-254 (2015).

2. S. Miyazaki, S. Kimura, F. Takei, T. Miura, K. Otsuka, and Y. Suzuki, "Shape memory effect and pseudoelasticity in a TiNi single crystal," Scr. Metall., 17, No. 9, 1057-1062 (1983).

3. F. Auricchio, E. Boatti, and M. Conti, "SMA biomedical applications," in: L. Lecce and A. Concilio (editors), Shape Memory Alloy Engineering, Butterworth-Heinemann, Boston (2015), pp. 307-341.

4. V. Torra, C. Auguet, G. Carreras, L. Dieng, F. C. Lovey, and P. Terriault, "The SMA: An effective damper in civil engineering that smoothes oscillations,” Mater. Sci. Forum, 706-709, 2020-2025 (2012). 
5. P. Yasniy, M. Kolisnyk, O. Kononchuk, and V. Iasnii, “Calculation of constructive parameters of SMA damper,” Sci. J. TNTU, 88, No. 4, 7-15 (2017).

6. D. J. Hartl and D. C. Lagoudas, "Aerospace applications of shape memory alloys," Proc. Inst. Mech. Eng. Part G. J. Aerosp. Eng., 221, No. 4, 535-552 (2007).

7. S. W. Robertson, A. R. Pelton, and R. O. Ritchie, "Mechanical fatigue and fracture of Nitinol," Int. Mat. Reviews, 57, No. 1, 1-36 (2012).

8. V. Iasnii, P. Yasniy, Yu. Lapusta, and T. Shnitsar, "Experimental study of pseudoelastic NiTi alloy under cyclic loading," Sci. J. TNTU, 92, No. 4, 7-12 (2018).

9. V. P. Iasnii, H. M. Nykyforchyn, O. T. Tsyrul'nyk, and O. Z. Student, "Specific features of deformation of the nitinol alloy after electrolytic hydrogenation," Fiz.-Khim. Mekh. Mater., 54, No. 4, 124-130 (2018); English translation: Mater. Sci., 54, No. 4, 582-588 (2019).

10. V. Iasnii and P. Yasniy, "Influence of stress ratio on functional fatigue of pseudoelastic NiTi alloy," Proced. Struct. Integrity, 16, 67-72 (2019).

11. V. Iasnii and P. Yasniy, "Degradation of functional properties of pseudoelastic NiTi alloy under cyclic loading: an experimental study," Acta Mech. Autom., 13, No. 2, 95-100 (2019).

12. O. Z. Student, W. Dudzinski, H. M. Nykyforchyn, and A. Kaminska, "Effect of high-temperature degradation of heat-resistant steel on mechanical and fractographic peculiarities of fatigue crack growth," Fiz.-Khim. Mekh. Mater., 34, No. 4, 49-58 (1999); English translation: Mater. Sci., 35, No. 4, 499-508 (1999).

13. P. O. Maruschak, D. Ya. Baran, A. P. Sorochak, R. T. Bishchak, and V. P. Yasnii, "Cyclic crack resistance and micromechanisms of fracture of steel 25Kh1M1F," Strength Mater., 44, No. 4, 410-418 (2012).

14. L. Poberezhnyi, P. Maruschak, O. Prentkovskis, I. Danyliuk, T. Pyrig, and J. Brezinová "Fatigue and failure of steel of offshore gas pipeline after the laying operation," Arch. Civil Mech.Eng., 16, No. 3, 524-536 (2016).

15. Y. Murakami and R. O. Ritchie, "Effects of hydrogen on fatigue-crack propagation in steels," in: R. P. Gangloff and B. P. Somerday (editors), Gaseous Hydrogen Embrittlement of Materials in Energy Technologies: The Problem, Its Characterization and Effects on Particular Alloy Classes, Vol. 1, Woodhead Publ., Cambridge (2012), pp. 379-417.

16. V. P. Iasnii, O. Z. Student, and H. M. Nykyforchyn, "Influence of hydrogenation on the fracture of nitinol alloy in tension," Fiz.Khim. Mekh.Mater., 54, No. 3, 80-85 (2019); English translation: Mater. Sci., 55, No. 3, 386-391 (2019). 